\title{
Detection of trisomies 13, 18 and 21 using non-invasive prenatal testing
}

\author{
RONG QIANG $^{1,2}$, NA CAI $^{1}$, XIAOBIN WANG $^{1}$, LIN WANG $^{1}, \mathrm{KE} \mathrm{CUI}^{1}, \mathrm{WEI} \mathrm{WANG}^{3}, \mathrm{XIANG} \mathrm{WANG}^{4}$ and XU LI ${ }^{2}$ \\ ${ }^{1}$ Genetic Medical Center, Northwest Women and Children's Hospital, Xi'an, Shaanxi 710003; \\ ${ }^{2}$ Center for Translational Medicine, The First Affiliated Hospital of Xi'an Jiaotong University, Xi'an, Shaanxi 710061; \\ ${ }^{3}$ Shenzhen BGI Clinical Laboratory Center, Shenzhen, Guangdong 518083; ${ }^{4}$ Genetics and Department of Gynecology, \\ The First Affiliated Hospital of Xi'an Jiaotong University, Xi'an, Shaanxi 710061, P.R. China
}

Received July 11, 2016; Accepted December 20, 2016

DOI: $10.3892 /$ etm.2017.4272

\begin{abstract}
The clinical performance of non-invasive prenatal testing (NIPT) in the Down's syndrome screening based on 1,901 pregnant women in a Chinese hospital was investigated. This was a retrospective analysis of NIPT study in singleton pregnancy $(n=1,901)$. The NIPT test is offered routinely as a prenatal screening test for common fetal aneuploidies, including trisomy 13 (T13), T18 and T21 to pregnant women with risk factors of one or more anomalies. Maternal peripheral blood $(5 \mathrm{ml})$ was collected in an ethylenediaminetetraacetic acid (EDTA) tube at a gestational age of $12+0$ to $32+6$ weeks The samples were delivered at $-80^{\circ} \mathrm{C}$ to the certified Shenzhen BGI Clinical Laboratory Center. Sequencing data were analyzed using a proprietary algorithm. Women with positive NIPT results were recommended to receive karyotype analysis and amniotic fluid puncture for further validation. The cases were followed up for 56 days after delivery. All the patients underwent ultrasound examination, and the majority of patients $(91.16 \%)$ showed normal findings. In contrast, $136(7.15 \%)$ showed ultrasound anomalies. The most common anomaly was echogenic heart focus $(n=80)$, accounting for $4.21 \%$ of the patients. Twenty-two cases were classified by the NIPT to be positive for the T21 $(n=15)$, T18 $(n=5)$ and T13 $(n=2)$, respectively, while the others $(n=1,879)$ were classified to be NIPT negative cases. Among these cases, the fetal outcome data were obtained in 1,483 cases, while 396 were lost to follow-up. The majority of cases $(75.47 \%)$ were normal at birth. Neonatal death was observed in 1 case. Five pregnant women decided termination of pregnancy despite the presence of NIPT negativity. In conclusion, NIPT technique is feasible for the prenatal screening of T18 and T21 with higher sensitivity and specificity compared with conventional methods.
\end{abstract}

Correspondence to: $\mathrm{Dr} \mathrm{Xu} \mathrm{Li}$, Center for Translational Medicine, The First Affiliated Hospital of Xi'an Jiaotong University, 277 Yanta Road, Xi'an, Shaanxi 710061, P.R. China

E-mail: lixu20160204@163.com

Key words: Down's syndrome, non-invasive prenatal testing, prenatal screening, trisomy

\section{Introduction}

Down's syndrome screening is offered to all pregnant women in many counties (1). Conventionally, the combined screening test involving fetal ultrasound examination and maternal serum biomarkers determination (2) is used to generate a risk assessment. Generally, such a procedure is performed at a gestational age of 10 weeks and $14+1$ weeks with a rate of detection $\sim 85 \%$ with a rate of false positive of $2.5 \%$ (3).

To the best of our knowledge, the majority of pregnant women wanted to be informed if Down's syndrome was suspected. On clinical suspicion, most of them would prefer to undergo an invasive diagnostic procedure, which is currently the main method in clinical practice. Accordingly, invasive tests may carry a risk of miscarriage of $\sim 0.5 \%$ (4). Extensive studies have been focused on developing an alternative method with highflyer or equal accuracy and non-invasive features $(5,6)$. Non-invasive prenatal testing (NIPT) for fetal aneuploidies is now available and is generally suggested as a screening test in clinical practice (7). Up to now, NIPT has been considered as committee opinions or guidelines for the clinical screening for the more common autosomal trisomies, such as trisomy 13 (T13), T18 and T21 $(8,9)$. However, only few studies have reported the use of NIPT for the prenatal screening of Down's syndrome due to small sample size.

In the present study, we report a performance evaluation of NIPT-based Down's syndrome screening in our hospital with a large patient cohort of 1,901 singleton pregnancies. Our study indicated that NIPT is feasible for the prenatal screening of T18 and T21 with higher sensitivity and specificity for the Down's syndrome screening, compared with conventional methods.

\section{Patients and methods}

Patients. The study protocols were approved by the Ethics Committee of Maternal and Children's Hospital of Shaanxi Province (Xi'an, China). Written informed consent was obtained from each patient. The study was a retrospective analysis of NIPT in singleton pregnancy over the period from March 2012 to March 2015 at the Maternal and Children's 
Table I. Basic characteristics of the 1,901 pregnant women of NIPT.

\begin{tabular}{|c|c|}
\hline Characteristics & No. $(\%)$ \\
\hline \multicolumn{2}{|l|}{ Maternal age (years) } \\
\hline$\leq 20$ & $0.21 \%(4 / 1,901)$ \\
\hline $20-24$ & $8.63 \%(164 / 1,901)$ \\
\hline $25-29$ & $40.50 \%(770 / 1,901)$ \\
\hline $30-34$ & $25.25 \%(480 / 1,901)$ \\
\hline $35-39$ & $21.25 \%(404 / 1,901)$ \\
\hline $40-44$ & $4.00 \%(76 / 1,901)$ \\
\hline$\geq 45$ & $0.16 \%(3 / 1,901)$ \\
\hline Mean & 30.57 \\
\hline Range & $19-45$ \\
\hline \multicolumn{2}{|l|}{ Gestation at NIPT test (weeks) } \\
\hline $12+0$ to $12+6$ & $1.00 \%(19 / 1,901)$ \\
\hline $13+0$ to $13+6$ & $1.63 \%(31 / 1,901)$ \\
\hline $14+0$ to $14+6$ & $1.68 \%(32 / 1,901)$ \\
\hline $15+0$ to $15+6$ & $3.26 \%(62 / 1,901)$ \\
\hline $16+0$ to $16+6$ & $7.26 \%(138 / 1,901)$ \\
\hline $17+0$ to $17+6$ & $17.31 \%(329 / 1,901)$ \\
\hline $18+0$ to $18+6$ & $21.25 \%(404 / 1,901)$ \\
\hline $19+0$ to $19+6$ & $16.10 \%(306 / 1,901)$ \\
\hline $20+0$ to $20+6$ & $10.89 \%(207 / 1,901)$ \\
\hline $21+0$ to $21+6$ & $8.15 \%(155 / 1,901)$ \\
\hline $22+0$ to $22+6$ & $4.73 \%(90 / 1,901)$ \\
\hline $23+0$ to $23+6$ & $3.16 \%(60 / 1,901)$ \\
\hline $24+0$ to $24+6$ & $1.53 \%(29 / 1,901)$ \\
\hline $25+0$ to $25+6$ & $0.68 \%(13 / 1,901)$ \\
\hline $26+0$ to $26+6$ & $0.58 \%(11 / 1,901)$ \\
\hline $27+0$ to $27+6$ & $0.11 \%(2 / 1,901)$ \\
\hline $28+0$ to $28+6$ & $0.16 \%(3 / 1,901)$ \\
\hline $29+0$ to $29+6$ & $0.00 \%(0 / 1,901)$ \\
\hline $30+0$ to $30+6$ & $0.11 \%(2 / 1,901)$ \\
\hline $31+0$ to $31+6$ & $0.11 \%(2 / 1,901)$ \\
\hline $32+0$ to $32+6$ & $0.05 \%(1 / 1,901)$ \\
\hline Unknown & $0.26 \%(5 / 1,901)$ \\
\hline \multicolumn{2}{|l|}{ Ultrasound findings } \\
\hline Normal & $91.16 \%(1733 / 1,901)$ \\
\hline Unknown & $1.63 \%(31 / 1,901)$ \\
\hline Abnormal ultrasonographic soft markers or ultrasound anomalies & $7.15 \%(136 / 1,901)$ \\
\hline Thickened NT/NF & $0.16 \%(3 / 1,901)$ \\
\hline Echogenic heart focus & $4.21 \%(80 / 1,901)$ \\
\hline Renal pelvic dilatation & $0.11 \%(2 / 1,901)$ \\
\hline Echogenic heart focus + renal pelvic dilatation & $0.16 \%(3 / 1,901)$ \\
\hline Echogenic heart focus + renal pelvic dilatation + choroid plexus cysts & $0.05 \%(1 / 1,901)$ \\
\hline Renal pelvic dilatation + widened ventricle & $0.05 \%(1 / 1,901)$ \\
\hline Echogenic heart focus + choroid plexus cysts & $0.16 \%(3 / 1,901)$ \\
\hline Choroid plexus cysts & $0.42 \%(8 / 1,901)$ \\
\hline Widened ventricle & $0.26 \%(5 / 1,901)$ \\
\hline Echogenic heart focus + widened ventricle & $0.21 \%(4 / 1,901)$ \\
\hline
\end{tabular}


Table I. Continued.

Characteristics

Echogenic heart focus + widened ventricle + small nasal bone

Echogenic heart focus + widened ventricle + thickened NF

Echogenic bowel

Echogenic heart focus + echogenic bowel

Absent nasal bone

Echogenic heart focus + small nasal bone

Tricuspid regurgitation

Others

Prior screening test

High risk (T21)

Critical high risk (T21)

High risk (T18)

Critical high risk (T18)

High risk (T21+T18)

Critical high risk (T21+T18)

Low risk

None

Unknown

Previous trisomy 21 pregnancies

Pregnancy by assisted reproductive techniques
No. $(\%)$
$0.05 \%(1 / 1,901)$
$0.05 \%(1 / 1,901)$
$0.16 \%(3 / 1,901)$
$0.05 \%(1 / 1,901)$
$0.05 \%(1 / 1,901)$
$0.05 \%(1 / 1,901)$
$0.05 \%(1 / 1,901)$
$0.89 \%(17 / 1,901)$

$49.55 \%(942 / 1,901)$

$14.94 \%(284 / 1,901)$

$1.16 \%(22 / 1,901)$

$0.16 \%(3 / 1,901)$

$0.11 \%(2 / 1,901)$

$0.11 \%(2 / 1,901)$

$3.58 \%(68 / 1,901)$

$28.83 \%(548 / 1,901)$

$1.58 \%(30 / 1,901)$

$0.32 \%(6 / 1,901)$

$1.53 \%(29 / 1,901)$

NIPT, non-invasive prenatal testing.

Hospital of Shaanxi Province. The prenatal screening test findings for common fetal aneuploidies, including T13, T18 and T21, were set as previously described (10). The NIPT test is offered routinely as a prenatal screening test for common fetal aneuploidies, including T13, T18 and T21 to pregnant women with risk factors of one or more anomaly. In total, 1,901 pregnant women (19-45 years, median 30.57 years) received the NIPT test, and all received prior prenatal screening (Down's syndrome screening).

Sequencing. Maternal peripheral blood $(5 \mathrm{ml})$ was collected in an ethylenediaminetetraacetic acid (EDTA) tube at a gestational age of $12+0$ to $35+6$ weeks. The blood sample was stored at $4^{\circ} \mathrm{C}$ immediately after collection. Plasma was isolated within $8 \mathrm{~h}$ with a two-step centrifugation protocol according to the previous description (11). Subsequently, samples were delivered at $-80^{\circ} \mathrm{C}$ to the ISO/IEC 17025 (International Organization for Standardization/International Electro technical Commission)-certified at Shenzhen BGI Clinical Laboratory Center (Shenzhen, China). The cell-free DNA extraction, library construction, sequencing, and bioinformatics analysis were performed according to the previous study (11).

Bioinformatics analysis. Sequencing data were analyzed using a proprietary algorithm. The binary hypothesis T-score of particular chromosomes in each sample was determined, as reported previously (11). Briefly, to assess the fetal risk of T21,
T18 and T13, the sample with a T-score $\geq 3$.0 for these chromosomes was classified as positive, whereas a T-score $<3.0$ was classified as negative for the indicated trisomy.

Karyotype analysis and amniotic fluid puncture. Women with positive NIPT results were recommended to receive karyotype analysis and amniotic fluid puncture for further validation. The amniotic fluid puncture was performed as routinely described. The karyotype analysis was performed according to the International System for Human Cytogenetic Nomenclature guidelines (12).

Follow-up. Follow-up was performed to NIPT negativity cases via telecommunication. The follow-up duration was 56 days after delivery. A total of 396 cases were lost to follow-up.

\section{Results}

Patient characteristics. A total of 1,901 pregnant women of Han Chinese background, with a mean maternal age of 30.57 years (19-45 years), were included in this study. The gestational age was from 12 weeks to $32+6$ weeks at blood sample collection. The patient characteristics were listed in Table I. All these patients received prior screening tests using conventional methods previously, and most of them were classified as risks for T21 and/or T18. However, among these patients, 22 cases were classified by the NIPT to be positive for the T21 $(n=15), T 18(n=5)$ and T13 $(n=2)$, respectively. 
Table II. Details of the 22 non-invasive prenatal testing (NIPT) positive cases.

\begin{tabular}{|c|c|c|c|c|c|c|c|c|}
\hline \multirow[b]{2}{*}{ No. } & \multirow[b]{2}{*}{ Sample ID } & \multirow[b]{2}{*}{$\begin{array}{l}\text { Maternal } \\
\text { age, year }\end{array}$} & \multirow[b]{2}{*}{$\begin{array}{l}\text { Ultrasound } \\
\text { findings }\end{array}$} & \multirow[b]{2}{*}{$\begin{array}{c}\text { Prior screening } \\
\text { test results }\end{array}$} & \multirow[b]{2}{*}{$\begin{array}{l}\text { Gestation, } \\
\text { week }\end{array}$} & \multicolumn{2}{|c|}{ NIPT } & \multirow[b]{2}{*}{ Outcome } \\
\hline & & & & & & $\begin{array}{l}\text { High } \\
\text { risk for }\end{array}$ & $\begin{array}{c}\text { Fetal } \\
\text { karyotpe }\end{array}$ & \\
\hline 1 & 13B0148333 & 31 & Normal & $1: 45(\mathrm{~T} 21)$ & $21+5$ & $\mathrm{~T} 21$ & $47, \mathrm{XN},+21$ & Termination of pregnancy \\
\hline 2 & 13B0148379R & 37 & Normal & - & $22+5$ & $\mathrm{~T} 18$ & $46, \mathrm{XN}$ & Normal \\
\hline 3 & 14B1017282 & 38 & Normal & Unknown & 19 & $\mathrm{~T} 21$ & $47, \mathrm{XN},+21$ & Termination of pregnancy \\
\hline 4 & 14B1017311 & 32 & Normal & Unknown & $14+5$ & $\mathrm{~T} 21$ & $47, \mathrm{XN},+21$ & Termination of pregnancy \\
\hline 5 & 14B1017323 & 24 & Normal & $1: 26(\mathrm{~T} 21)$ & $17+2$ & $\mathrm{~T} 21$ & $47, \mathrm{XN},+21$ & Termination of pregnancy \\
\hline 6 & 15B1103208D & 29 & $\begin{array}{l}\text { A vanishing } \\
\text { twin }\end{array}$ & - & $16+2$ & $\mathrm{~T} 18$ & & Stillbirth \\
\hline 7 & PDB12AC00025 & 37 & Normal & $1: 33(\mathrm{~T} 21)$ & $17+2$ & $\mathrm{~T} 21$ & $47, \mathrm{XN},+21$ & Termination of pregnancy \\
\hline 8 & PDB12AC00114 & 34 & Normal & $1: 55(\mathrm{~T} 21)$ & $18+4$ & $\mathrm{~T} 21$ & - & Intrauterine fetal death \\
\hline 9 & PDB12AC00146 & 27 & $\begin{array}{l}\text { Echogenic } \\
\text { heart focus }\end{array}$ & $1: 25(\mathrm{~T} 21)$ & $20+2$ & $\mathrm{~T} 21$ & $47, \mathrm{XN},+21$ & Termination of pregnancy \\
\hline 10 & PDB13AC00011 & 31 & Normal & $1: 166(\mathrm{~T} 21)$ & $18+2$ & $\mathrm{~T} 21$ & $47, \mathrm{XN},+21$ & Termination of pregnancy \\
\hline 11 & PDB13AC00027R & 33 & Normal & 1:144 (T21) & 21 & $\mathrm{~T} 13$ & Declined & Termination of pregnancy \\
\hline 12 & PDB13AC00166 & 30 & Normal & $1: 140(\mathrm{~T} 21)$ & $18+3$ & $\mathrm{~T} 21$ & $47, \mathrm{XN},+21$ & Termination of pregnancy \\
\hline 13 & PDB13AC00213R & 33 & Normal & 1:100 (T21) & 22 & $\mathrm{~T} 18$ & Declined & Termination of pregnancy \\
\hline 14 & PDB13AC00484R & 28 & Normal & $1: 20(\mathrm{~T} 21)$ & $18+2$ & $\mathrm{~T} 21$ & - & Intrauterine fetal death \\
\hline 15 & PDB13AC00485 & 33 & Normal & $1: 37(\mathrm{~T} 21)$ & $16+5$ & $\mathrm{~T} 21$ & Declined & Loss to follow up \\
\hline 16 & PDB13AC00614 & 29 & $\begin{array}{l}\text { Echogenic } \\
\text { heart focus }\end{array}$ & $1: 280(\mathrm{~T} 21)$ & $21+5$ & $\mathrm{~T} 21$ & $47, \mathrm{XN},+21$ & Termination of pregnancy \\
\hline 17 & PDB13AC00729 & 31 & Norma & $1: 270(\mathrm{~T} 21)$ & $18+6$ & $\mathrm{~T} 21$ & $47, \mathrm{XN},+21$ & Termination of pregnancy \\
\hline 18 & PDB13AC00834 & 30 & Normal & $1: 260(\mathrm{~T} 21)$ & $15+5$ & $\mathrm{~T} 13$ & $46, \mathrm{XN}$ & Normal \\
\hline 19 & PDB13AC00952 & 40 & Normal & - & $12+5$ & $\mathrm{~T} 21$ & $47, \mathrm{XN},+21$ & Termination of pregnancy \\
\hline 20 & PDB13AC01023 & 24 & Normal & $1: 270(\mathrm{~T} 21)$ & $19+5$ & $\mathrm{~T} 18$ & $\begin{array}{c}\text { 47,XY, } \\
+18(70 \%) \\
\text { 48,XYY, } \\
+18(30 \%)\end{array}$ & Termination of pregnancy \\
\hline 21 & PDB13AC01225 & 22 & Normal & 1:177 (Т21) & $19+2$ & $\mathrm{~T} 21$ & $47, \mathrm{XN},+21$ & Termination of pregnancy \\
\hline 22 & PDB13AC01245R & 27 & Normal & $1: 270(\mathrm{~T} 21)$ & 21 & $\mathrm{~T} 18$ & $46, \mathrm{XN}$ & Normal \\
\hline
\end{tabular}

While the others $(n=1,879)$ were classified to be NIPT negative cases.

Karyotype confirmation. Among the 22 pregnant women confirmed with positivity of NIPT tests, 15 showed high risks for T21, 5 showed high risks for T18 and 2 showed high risks for T13, respectively (Table II). Finally, 16 underwent amniotic fluid puncture for further validation. Among the 15 cases with high risks of T21, the karyotype results were confirmed with T21 in 12 cases, while the other 3 refused the amniotic fluid puncture. Three underwent amniotic fluid puncture among the 5 cases with high risk of T18. Karyotype results indicated normal karyotype in 2 patients, while the other one showed karyotype of 47, XY,+18 (70\%) and 48, XYY,+18 (30\%). Among the 2 cases with high risks of T13, 1 declined to receive the amniotic fluid puncture, while the other 1 showed a normal karyotype.

Pregnancy outcome. The fetal outcome data for the 6 pregnant women with NIPT-positivity but declined to undergo amniotic fluid puncture were obtained after the expected
Table III. The pregnancy outcome of 1,879 NIPT negative cases.

Follow-up

Fetal outcome available

Confirmed normal at birth

Still birth

Neonatal death

Termination of pregnancy

Abnormal ultrasound findings

Abnormal ultrasound findings-

chromosomal abnormalities

Personal reason

Loss to follow-up

Failed to contact

$396(21.08)$

Refused to provide information

$$
6(0.32)
$$

NIPT, non-invasive prenatal testing. 
Table IV. Comparison of specificity (Sp) and sensitivity (Se) of NIPT and prior screening test.

A, T21

\begin{tabular}{|c|c|c|c|c|c|c|c|c|c|c|c|}
\hline \multirow[b]{2}{*}{ Results } & \multicolumn{5}{|c|}{ Prior screening test } & \multicolumn{5}{|c|}{ NIPT } & \multirow[b]{2}{*}{ Validation } \\
\hline & No. & $\mathrm{Se}$ & $\mathrm{Sp}$ & FPV & PPV & Positive & $\mathrm{Se}$ & $\mathrm{Sp}$ & FPV & PPV & \\
\hline High risk & 752 & $88.89 \%$ & $29.08 \%$ & $70.92 \%$ & $1.06 \%$ & 10 & $100 \%$ & $100 \%$ & $0 \%$ & $100 \%$ & $\begin{array}{c}8(47, \mathrm{XN},+21) ; 2 \text { (Intrauterine } \\
\text { fetal death) }\end{array}$ \\
\hline $\begin{array}{l}\text { Critical } \\
\text { high risk }\end{array}$ & 234 & $88.89 \%$ & $29.08 \%$ & $70.92 \%$ & $1.06 \%$ & 1 & $100 \%$ & $100 \%$ & $0 \%$ & $100 \%$ & $1(47, \mathrm{XN},+21)$ \\
\hline Low risk & 72 & $88.89 \%$ & $29.08 \%$ & $70.92 \%$ & $1.06 \%$ & 0 & $100 \%$ & $100 \%$ & $0 \%$ & $100 \%$ & - \\
\hline None & 377 & - & - & - & - & 1 & $100 \%$ & $100 \%$ & $0 \%$ & $100 \%$ & $1(47, \mathrm{XN},+21)$ \\
\hline Unknown & 9 & - & - & - & - & 2 & $100 \%$ & $100 \%$ & $0 \%$ & $100 \%$ & $2(47, \mathrm{XN},+21)$ \\
\hline Total & 1,444 & - & - & - & - & 14 & $100 \%$ & $100 \%$ & $0 \%$ & $100 \%$ & $\begin{array}{c}12(47, \mathrm{XN},+21) ; 2(\text { Intrauterine } \\
\text { fetal death) }\end{array}$ \\
\hline
\end{tabular}

B, T18

Prior screening test $\quad$ NIPT

$\begin{array}{lllllllllllll} & \text { Results } & \text { No. } & \text { Se } & \text { Sp } & \text { FPV } & \text { PPV } & \text { Positive } & \text { Se } & \text { Sp } & \text { FPV } & \text { PPV } & \text { Validation }\end{array}$

\begin{tabular}{lrlllllllllll}
\hline High risk & 19 & $0 \%$ & $98.20 \%$ & $1.80 \%$ & $0 / 0+10$ & 0 & $100 \%$ & $99.86 \%$ & $0.14 \%$ & $33.33 \%$ & - \\
Critical & 4 & $0 \%$ & $98.20 \%$ & $1.80 \%$ & $0 / 0+10$ & 0 & $100 \%$ & $99.86 \%$ & $0.14 \%$ & $33.33 \%$ & -
\end{tabular}

high risk

$\begin{array}{llllllllll}\text { Low risk } & 1,035 & 0 \% & 98.20 \% & 1.80 \% & 0 / 0+10 \quad 3 & 100 \% & 99.86 \% & 0.14 \% & 33.33 \%\end{array}$

$1[47, \mathrm{XY},+18(70 \%)$;

48,XYY,+18(30\%)];

1 (Termination of pregnancy);

$1(46, \mathrm{XN})$

$1(46, \mathrm{XN})$

$\begin{array}{lrlllllllll}\text { None } & 377 & - & - & - & - & 1 & 100 \% & 99.86 \% & 0.14 \% & 33.33 \% \\ \text { Unknown } & 9 & - & - & - & - & 0 & 100 \% & 99.86 \% & 0.14 \% & 33.33 \% \\ \text { Total } & 1,444 & - & - & - & - & 4 & 100 \% & 99.86 \% & 0.14 \% & 33.33 \%\end{array}$

$1[47, X Y,+18(70 \%)$;

48,XYY,+18(30\%)];

1(Terminationof pregnancy); $2(46, \mathrm{XN})$

C, T13

\begin{tabular}{|c|c|c|c|c|c|c|c|c|c|c|c|}
\hline \multirow[b]{2}{*}{ Results } & \multicolumn{5}{|c|}{ Prior screening test } & \multicolumn{5}{|c|}{ NIPT } & \multirow[b]{2}{*}{ Validation } \\
\hline & No. & $\mathrm{Se}$ & $\mathrm{Sp}$ & FPV & PPV & Positive & $\mathrm{Se}$ & $\mathrm{Sp}$ & FPV & PPV & \\
\hline Total & - & - & - & - & - & 2 & $0 \%$ & $99.93 \%$ & $0.07 \%$ & $0 \%$ & $\begin{array}{c}1 \text { (Termination of pregnancy); } \\
1(46, \mathrm{XN})\end{array}$ \\
\hline
\end{tabular}

NIPT, non-invasive prenatal testing.

confinement date. All the 12 pregnant women validated with T21 through karyotype decided termination of pregnancy. For the 3 pregnant women with NIPT-positivity declining to receive amniotic fluid puncture, the fetal outcome in 2 cases were intrauterine fetal death while the other 1 was lost in the follow-up. One pregnant with NIPT positivity with high risks for T18 still decided delivery without undergoing amniotic fluid puncture. Another two pregnant women with NIPT positivity with high risks for T13 and T18 decided to determine the pregnancy. One pregnant woman decided to terminate the pregnancy after classified as NIPT positivity after karyotype analysis (Table II).

In the 1,879 cases with negative NIPT testing, the fetal outcome data were obtained in 1,483 cases, while 396 were in lost. The majority of cases $(75.47 \%)$ were normal at birth. Neonatal death was observed in 1 case. Five pregnant women 
decided termination of pregnancy despite the presence of NIPT negativity (Table III).

Evaluation of NIPT capacity. Among the 1,879 cases with NIPT negativity, follow-up was successfully performed in 1,504 cases including 21 with NIPT positivity and 1,483 with NIPT negativity. The stillbirth cases $(n=60)$ were excluded from the NIPT performance evaluation. Thus, a total of 1,444 cases were used for the analysis finally. The sensitivity of the prior screening test for T21 was $88.89 \%$, but the specificity was only $29.13 \%$ (Table IV). Among the 15 cases classified as NIPT positivity for T21, one patient was lost in the follow-up. Thus, 14 patients were included in the analysis, and the sensitivity and specificity were both at $100 \%$. For the conventional screening test, the respective sensitivity and specificity for the T18, were 73.27 and $98.20 \%$ while the sensitivity and specificity for the NIPT were 100 and $99.86 \%$, respectively (Table IV).

\section{Discussion}

NIPT has been widely used for the prenatal screening of T21, T18 and T13 in the last few years. Up to now, it is still lacking large scale clinical studies focused on the efficiency in the general population. Besides, there are really some concerns on the clinical performance. The present study including 1,901 cases was performed to investigate the clinical performance of NIPT on the sensitivity and specificity on the screening of T21, T18 and T13, respectively.

Conventional prenatal screening involves amniotic fluid puncture, chorionic villus sampling and umbilical vein puncture (13). However, these methods are invasive and cause high risks of infection, and even abortion. Recently, NIPT for common fetal aneuploidies by massively parallel sequencing of maternal plasma DNA has been considered as a screening method in clinical practices (14). Up to now, several studies have been carried out to focus on the application of such a technique on the screening for the T13, T18 and T21 (14-16). For example, Liang and collegues reported the efficiency of NIPT based on 412 samples with full karyotyping and sequencing results (11). These authors showed a detection sensitivity of $100 \%$ and a specificity of $99.71 \%$, and indicated that the NIPT of fetal chromosome aneuploidies for all 24 chromosomes was feasible in a single sequencing event. In our study, a large sample size with a total of 1,901 cases was used. On this basis, we evaluated the efficiency and clinical performance of NIPT in the screening for the T13, T18 and T21, respectively. We found that, among the 22 NIPT-positive pregnant women, all chose to be informed of the potential results, suggesting that most of the pregnant women want to know the potential information as much as possible in order to make the final decision. Most of the patients $(86.3 \%)$ decided to undergo amniotic fluid puncture. For the cases $(n=1483)$ with negative NIPT findings, 1,418 (95.61\%) were normal at birth, indicating the efficiency of NIPT screening was extremely feasible as previously described in other studies.

Serum screening technique has been commonly used in the clinical practice in the past decades. Giving an estimated detection sensitivity of $90 \%$ and a rate of false positivity of $2-5 \%$; the most commonly used method for the screening of Down syndrome and T18 being based on the combination of maternal age, ultrasound examination findings of the fetus, as well as the concentration of related markers $(17,18)$. Such a method is labor-consuming and involves extensive procedures. Invasive methods with amniocentesis as a representative method, is effective for the prescreening with definite results, but such a technique bears a miscarriage rate of $0.5 \%$ (10). Compared with these methods, the NIPT technique is non-invasive (with only a blood sample collection of $<10 \mathrm{ml}$ ) and easy to perform. In 2012, the committee of Prenatal Diagnosis in China gave positive opinion on the NIPT technique (19). On this basis, it is reasonable to believe that the application of NIPT in clinical practice may be further extended.

Indeed, the NIPT is suitable to the screening of pregnant women at a gestational age of $12+0$ to $26+6$ weeks, which is more extensive than the serum screening $(12+0$ to $16+6$ weeks) and amniotic fluid puncture ( $16+0$ to $22+6$ weeks), respectively (3). Another advantage of the NIPT is the satisfactory sensitivity and specificity (20). In our study, the sensitivity of the prior screening test for T21 was $88.89 \%$, but the specificity was only $29.13 \%$ while the NIPT showed $100 \%$ for both sensitivity and specificity for T21 screening. For the T18, the sensitivity and specificity was, respectively, 73.27 and $98.20 \%$ for the conventional screening test relatively to 100 and $99.86 \%$ for NIPT. Compared with the conventional methods, the sensitivity and specificity of NIPT for the screening of T18 and T21 was remarkably higher. However, the sensitivity of detection of T13 was $99.93 \%$, but the specificity was not satisfactory, suggesting that large samples are still needed to focus on the performance of NIPT for the screening of T13.

In conclusion, NIPT technique is feasible for the prenatal screening of T18 and T21 with higher sensitivity and specificity compared with conventional methods. We believe that the genome sequencing-based NIPT technique is applicable in clinical practice, and deserves extensive application in future.

\section{References}

1. Malone FD, Canick JA, Ball RH, Nyberg DA, Comstock CH, Bukowski R, Berkowitz RL, Gross SJ, Dugoff L, Craigo SD, et al; First- and Second-Trimester Evaluation of Risk (FASTER) Research Consortium: First-trimester or second-trimester screening, or both, for Down's syndrome. N Engl J Med 353: 2001-2011, 2005.

2. Haddow JE, Palomaki GE, Knight GJ, Williams J, Miller WA and Johnson A: Screening of maternal serum for fetal Down's syndrome in the first trimester. N Engl J Med 338: 955-961, 1998.

3. Nicolaides KH, Syngelaki A, Ashoor G, Birdir C and Touzet G: Noninvasive prenatal testing for fetal trisomies in a routinely screened first-trimester population. Am J Obstet Gynecol 207: 374.e1-374.e6, 2012.

4. Tabor A and Alfirevic Z: Update on procedure-related risks for prenatal diagnosis techniques. Fetal Diagn Ther 27: 1-7, 2010.

5. Wright $\mathrm{CF}$ and Burton $\mathrm{H}$ : The use of cell-free fetal nucleic acids in maternal blood for non-invasive prenatal diagnosis. Hum Reprod Update 15: 139-151, 2009.

6. de Jong A, Dondorp WJ, de Die-Smulders CEM, Frints SGM and de Wert GMWR: Non-invasive prenatal testing: Ethical issues explored. Eur J Hum Genet 18: 272-277, 2010.

7. Norton ME, Brar H, Weiss J, Karimi A, Laurent LC, Caughey AB Rodriguez MH, Williams J III, Mitchell ME, Adair CD, et al: Non-Invasive Chromosomal Evaluation (NICE) Study: Results of a multicenter prospective cohort study for detection of fetal trisomy 21 and trisomy 18. Am J Obstet Gynecol 207: 137.e1-137. e8, 2012 . 
8. Mao J, Wang T, Wang BJ, Liu YH, Li H, Zhang J, Cram D and Chen Y: Confined placental origin of the circulating cell free fetal DNA revealed by a discordant non-invasive prenatal test result in a trisomy 18 pregnancy. Clin Chim Acta 433: 190-193, 2014.

9. Garfield SS and Armstrong SO: Clinical and cost consequences of incorporating a novel non-invasive prenatal test into the diagnostic pathway for fetal trisomies. J Managed Care Med 15: 34-41, 2012.

10. Wald NJ, George L, Smith D, Densem JW and Petterson K; International Prenatal Screening Research Group: Serum screening for Down's syndrome between 8 and 14 weeks of pregnancy. Br J Obstet Gynaecol 103: 407-412, 1996.

11. Liang D, Lv W, Wang H, Xu L, Liu J, Li H, Hu L, Peng Y and Wu L: Non-invasive prenatal testing of fetal whole chromosome aneuploidy by massively parallel sequencing. Prenat Diagn 33 409-415, 2013.

12. Gonzalez Garcia JR and Meza-Espinoza JP: Use of the international system for human cytogenetic nomenclature (ISCN). Blood 108: 3952-3953, 2006.

13. Alfirevic Z, Sundberg K and Brigham S: Amniocentesis and chorionic villus sampling for prenatal diagnosis. Cochrane Database Syst Rev 1: 1-142, 2009.

14. Lau TK, Jiang FM, Stevenson RJ, Lo TK, Chan LW, Chan MK, Lo PSS, Wang W, Zhang HY, Chen F, et al: Secondary findings from non-invasive prenatal testing for common fetal aneuploidies by whole genome sequencing as a clinical service. Prenat Diagn 33: 602-608, 2013.
15. Song Y, Liu C, Qi H, Zhang Y, Bian X and Liu J: Noninvasive prenatal testing of fetal aneuploidies by massively parallel sequencing in a prospective Chinese population. Prenat Diagn 33: 700-706, 2013

16. Verweij EJ, de Boer MA and Oepkes D: Non-invasive prenatal testing for trisomy 13: More harm than good? Ultrasound Obstet Gynecol 44: 112-114, 2014.

17. Nicolaides KH, Spencer K, Avgidou K, Faiola S and Falcon O: Multicenter study of first-trimester screening for trisomy 21 in 75 821 pregnancies: Results and estimation of the potential impact of individual risk-orientated two-stage first-trimester screening. Ultrasound Obstet Gynecol 25: 221-226, 2005.

18. Rozenberg P, Bussières L, Chevret S, Bernard JP, Malagrida L, Cuckle H, Chabry C, Durand-Zaleski I, Bidat L, Lacroix I, et al: Screening for Down syndrome using first-trimester combined screening followed by second-trimester ultrasound examination in an unselected population. Am J Obstet Gynecol 195: $1379-1387,2006$

19. Yao H, Jiang F, Hu H, Gao Y, Zhu Z, Zhang H, Wang Y, Guo Y, Liu L, Yuan Y, et al: Detection of fetal sex chromosome aneuploidy by massively parallel sequencing of maternal plasma DNA: Initial experience in a Chinese hospital. Ultrasound Obstet Gynecol 44: 17-24, 2014.

20. Devers PL, Cronister A, Ormond KE, Facio F, Brasington CK and Flodman P: Noninvasive prenatal testing/noninvasive prenatal diagnosis: The position of the National Society of Genetic Counselors. J Genet Couns 22: 291-295, 2013. 